\title{
THE DISTRIBUTIONAL HISTORY OF CORACINA IN THE INDO-AUSTRALIAN ARCHIPELAGO
}

\author{
By \\ K. H. VOOUS AND J. G. VAN MARLE \\ (Zoological Museum, Amsterdam)
}

Recently RIPLEY (I94I) has prepared a systematic revision of the IndoAustralian members of the genus Coracina (Cuckoo-Shrike), which for a considerable time had been in a state of great confusion. RIPLEY's new arrangement represents a noteworthy step in the appreciation of the systematics of this difficult genus. Since only taxonomy and representative distribution have been taken into account by RIPLEY, resulting in the arrangement of 12 species into 3 superspecies and 7 isolated forms, certain problems still remain unsettled. It is the purpose of this paper to deal with some of these problems and to propose an arrangement of the Indo-Australian forms of Coracina not only in accordance with their taxonomy, but also with the history of their distribution. Special attention has been praid to the relative length and shape of the bill, which character RIPLEY almost entirely neglected. According to this method we have arrived at a somewhat different grouping, as will be discussed below.

This may be also the place to notice that, contrary to a recent opinion, brought forward by Delacour ( 1946) and others, we still consider the limits of the genus Coracina as opposed to Edolisoma, sufficiently defined by the different shapes of the bill.

The authors have been able to examine specimens of all species and of most races of the genus in the collections of the Leiden Museum, the Amstendam Museum, Van Marle-Coomans de Ruiter, and F. C. van Heurn.

In preparing this paper the authors have received much help from the excellent paper by ZEUNER (1943) on the evolutionary and distributional history of the Butterfly genus Troides. They are also much indebted to Mr. P. A. Clancé (Glasgow) for correcting the English of the manuscript.

\section{CORACINA STRIATA-GROUP (fig. 6)}

C. striata ranges throughout the following area: the Malay Peninsula, Singapore Island, Tioman Island, the islands in the Malacca Straits, Sumatra Bijdragen tot de Dierkunde, Afl. 28. 
(but apparently absent in Banka and Biliton), West-Sumatran Islands, Kangean, Rhio Archipelago, Anamba and Natuna Islands, Balabac, Palawan, Calamianes, Philippines, Sulu Islands, and Andamans. It is a lowland species in almost all parts of its range. Only in the Philippines, where other represen-

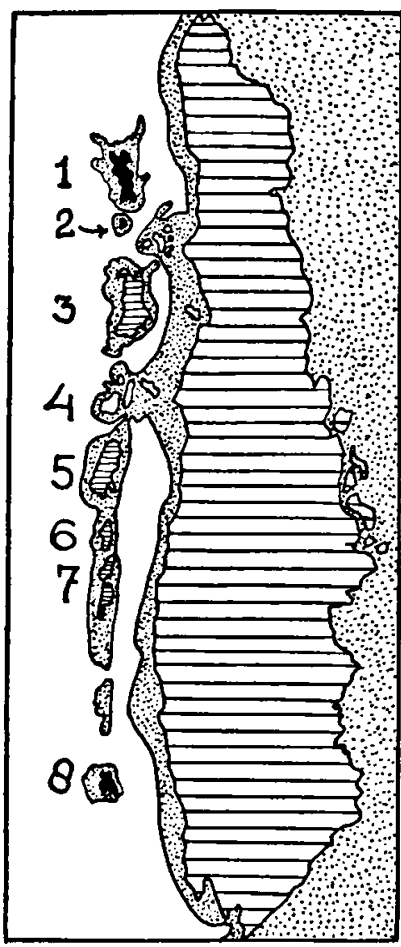

Fig. I. The forms of Coracina striata on the West-Sumatran Islands. The ranges of the races without barring in both sexes are black; those of the races which have ventrally barred females are striped. The sea-regions which lie above the $200 \mathrm{~m}$ depth-line are spotted. I Simalur, 2 Babi, 3 Nias, 4 Batu Islands, (5-7 Mentawei Islands), 5 Siberut. 6 Sipora, 7 North and South Pagai, 8 Engano. tatives of Coracina are absent, does it ascend to rather higher elevations, having been found up to $2100 \mathrm{~m}$ altitude (Delacour \& MaYr, I946). In the Eastern lowlands of the Malay Peninsula, Tioman Island, Rhio Archipelago, Sumatra, Siberut, Sipora, North and South Pagai, and Borneo, occurs the same subspecies (sumatrensis). This type of distribution apparently goes back to the last period of low sea-level, coinciding with the last glaciation in the northern hemisphere, when the Sunda Islands were connected with each other, forming the large tropical Sunda Basin.

In most of its races $C$. striata exhibits conspicuous secondary sexual differences, the males being uniform grey, whereas the females have the underparts transversely barred with dark grey and white. Wholly, or almost wholly, uniform grey birds, closely resembling the males of the other races, occur in both sexes of the subspecies inhabiting (I) the West-Sumatran Islands of Simalur, Babi, Banyak, and Engano, (2) Mindoro, Libagao, and Tablas, (3) Sulu Islands. These birds will be discussed separately.

(I) It is a known fact that during the Pleistocene periods of lower sea-levels (100-200 m) several West-Sumatran Islands (Mentawei Islands, Batu Islands, Nias) were connected to the Sumatran mainland, or brought very close together. Rather wide sea-channels remained between Sumatra and the islands of Simalur, Babi, and Engano, which are situated beyond the $-200 \mathrm{~m}$ line. The first group of West-Sumatran Islands are inhabited by the form sumatrensis, or a very slightly larger race, of which the female has a barred underside. The second group of islands (Simalur, Babi, and Engano), however, are inhabited by such races of $C$. striata (simalurensis, babiensis, enganensis), which are uniform grey in both sexes. These grey birds are presumed to be relicts of the older inhabitants of the Sunda Land, which must have been of a general grey colour type (fig. I). 
De Beaufort (1926) has given additional examples from the fauna of the West-Sumatran Islands, proving that Nias was at one time connected to Sumatra, whereas this does not seem to have been the case with the other islands. He mentions the total number of Reptiles, which had up to 1926 been recorded from each island, as also the number of those species which had also been found in Sumatra: Nias (64-24), Simalur (34-4), Mentawei Islands (34-4), Engano (I4-2). Although at that time the islands had been explored rather thoroughly, Nias had 6 known fresh-water fishes, whereas from Simalur only one species was known. DE BEAUfort summarizes his conclusions as follows: "It seems not improbable to me that the West-Sumatran Islands have been peopled via a Nias-Sumatra bridge, as has been also assumed by Dr. DE Roorj. In the late Tertiary this connection was broken, but it was re-established temporarily in the Pleistosene ice-period, when a new invasion penetrated into them, but could only reach Nias and the Batu Islands, and perhaps Simalur in a few cases only" (p. 78).

Though we must be extremely cautious assuming the earlier existence of land-bridges, nevertheless, it seems probable that the lowland Cuckoo-Shrikes could have reached Nias and the Mentawei Islands very easily during the last period of low sealevel. The recent inhabitants of these islands being identical with the race sumatrensis or being only slightly larger (Nias). This has not been the case with the islands of Simalur, Babi, and Engano, which were less accessible, their populations remaining isolated for a much longer period of time.

(2) Hydrographical and geological data seem to indicate that the Philippine Is!ands of Mindoro, Libagao, and Tablas (C. s. mindorensis), and (3) the Sulu Islands ( $C . s$. guillemardi) were probably not connected to the main Sunda Land during periods of non-maximum low sea-level, resulting in the fact that these islands were able to retain the original populations of Cuckoo-Shrikes. In keeping with the above findings, these binds are uniform grey in both sexes (fig. 2).

Situated just on the easternmost border of the Sunda Shelf, the Kangean Islands were connected to the main Sunda-lowland, at all events during the Pleistocene periods of maximum land-exposure. Consequently, surprise need not be expressed in finding that the generally distributed Sunda-lowland Cuckoo-Shrike ( $C$. striata) is represented by a relict on these islands, which, by the subsequent rising of the sea-level, were among the first to become isolated from the Sunda Land. Thus, C. s. vordermani from the Kangean Islands shows some morphological peculiarities, having more or less barred under tailcoverts in the male and almost uniform white ones in the female!

Apart from the above mentioned Philippine races in which both sexes are of a uniform grey colour, other Philippine Islands are inhabited by subspecies showing the same secondary sexual differences as are to be found in the race sumatrensis (Balabac, Palawan, Calam:anes, Lubang, Luzon, Polillo, Cebu). 
A third group of Philippine races consists of forms in which both sexes are ventrally barred (Ticao, Masbate, Panay, Guimaras, Negros, Bohol, Samar, Leyte, Panaon, Nipa, Mindanao, Basilan). As the latter races inhabit the most outwardly situated islands of the archipelago, we can suppose that the character geography of $C$. striata in the Philippines reveals a progressive clinal development in the direction Luzon ( $\sigma^{\top}$ uniform grey) to Mindanao

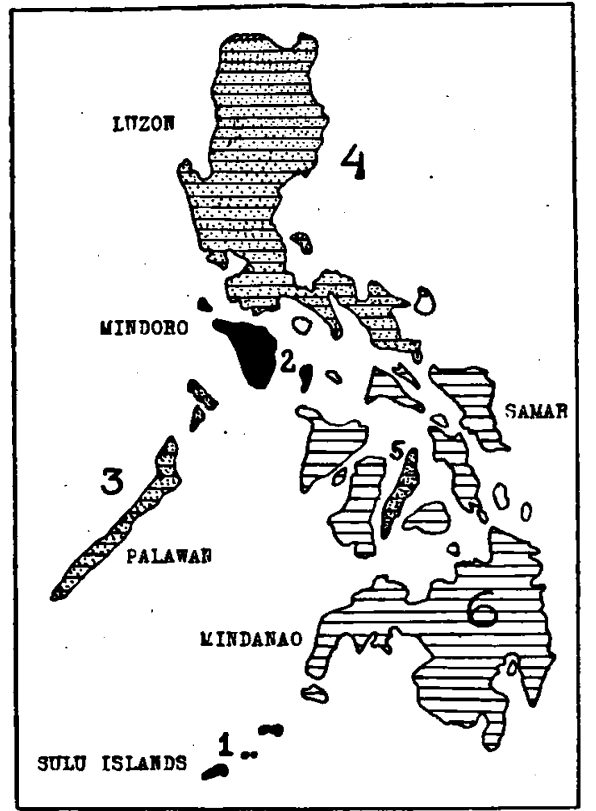

Fig. 2. The forms of Coracina striata in the Philippines. I-2 races without barring in both sexes, $3-5$ races with uniform grey males and ventrally barred females; 6 races with barred undersides in both sexes.
( $\sigma^{\top}$ barred black and white) (fig. 2). A perhaps not dissimilar case is that of the clinal variation of the Pigmy Woodpecker Dendrocopos maculatus discussed by one of us (Voous, 1947). Consequently, the barred underparts in the males of $C$. striata can be considered as having been acquired in a secondary manner!

We regret at not having been able to examine material of $C$. dobsoni from the Andaman Islands. This form has been treated as a race of striata by Ripley (1.c., p. $3^{88)}$ ) and others. The underparts of both sexes are said to be barred, though most obviously in the female. In keeping with the secondarily acquired barring of some of the Philippine races, the tendency to become barred, noticed in this Andaman form is also presumed to be a secondarily evolved character. $C$. $s$. dobsoni must apparently have come from the Malay Peninsula (see below).

In the above remarks we have tried to show that the recent distribution and character geography of $C$. striata indicates that this species has radiated from the tropical Sunda Basin, from whence it originated during the Pleistocene periods of low sea-level. In these times the Greater Sunda Islands were connected to each other and to the Malay Peninsula by extensive tropical lowlands; the Kangean, Anamba and Natuna Islands, Palawan and the Calamianes likewise formed part of the Sunda Land. A very close connection also existed with the Philippines, though in this archipelago large sea-basins prevented the formation of one solid land-mass. It is probable that the Sunda Basin with its - at present submerged - strongly meandering river-system, which empted into the South China Sea, "may adequately be compared with the Amazon system in its significance as a distributional centre for rainforest forms" (ZEUNER, 1943, p. I55). Consequently, those bird forms which 
at present inhabit the low-lying woodlands, especially the coastal plains, mangrove swamps, and jungles of the Greater Sunda Islands may safely be considered to have enjoyed at one time a continuous distribution. This is exactly the case in $C$. striata, as has already been pointed out above. Therefore, the assumption of a Pleistocene origin of this species in the Sunda Basin has a reasonably firm foundation. As the above discussed isolated forms of C. striata are uniform grey in both sexes, we can suppose that this coloration represents the ancestral type of striata, and that the barred underparts of the emales of most and the males of some races are the acquired characteristics of the species.

C. striata has no representative in Java. In contrast to the other Sunda Islands, Java is inhabited by another lowland form of Cuckoo-Shrike ( $C$. novachollandiae javensis), which is uniform grey in both sexes as in the older forms of striata, but possessing a uniform white abdomen and under-tailcoverts. As the island of Java was not connected to the Sunda Land during all Pleistocene periods of low sea-level, and its avifauna is known to possess a relatively large number of old Asiatic relict forms, we must suppose that C. novaehollandiae is the older inhabitant of Java, and of the Sunda Islands in general.

Unlike all other species of Coracina, the male of $C$. bicolor from Celebes has a uniform white underside and rump and black upperparts. The female is dark grey with black wings and tail and with a white rump, abdomen, and under-tailcoverts. Compared with other forms of Coracina, the bill of $C$. bicolor approaches in type only that of $C$. striata from the Philippines, though its bill is not black, but bluish grey. Ripley (1.c., p. 393) has given some additional evidence to show that bicolor may be a highly differentiated of fshoot of the striata-Group. C. bicolor is rather locally distributed in Celebes; its biotope being the edges of the lowland forests, where it inhabits the tops of the largest trees (STREsemanN, 1940). This points to it being an older inhabitant of Celebes than the second lowland form, $C$. leucopygia, which is everywhere common, but mainly in the cultivated regions. $C$. bicolor may have been a Pleistocene invader into Celebes, originating from the same stock as $C$. striata, reaching Celebes via the Philippines and the Sulu Islands. As a possible confirmatory evidence of this hypothesis we find that the Sulu Islands are inhabited by a form of striata (guilemardi), which is uniform dark grey in both sexes, this being the colour-type of the older forms of $C$. striata. The evolutionary history of bicolor and guillemardi is considered comparable with that of the Dwarf Woodpeckers Dendrocopos ramsayi from the Sulu Islands and $D$. temmincki from Celebes. As no Cuckoo-Shrikes are known from Sibuyan no comparison can be made with the evolutionary history of D. menagei, which is also an old Philippine form (cf. Voous, 1947). 


\section{CORACINA NOVAEHOLLANDIAE-GROUP (fig. 5)}

We have endeavoured to show above that $C$. novaehollandiae javensis from the lowlands of Java is an older inhabitant of the Sunda Islands than $C$. striata. RIPLEY (1.c.) has rightly - though somewhat drastically - added a great many forms to the species novaehollandiae, which in this new sense has got a large range, extending from Eastern Peninsular and Farther India, Southern China, Malacca, Andamans, Java, and the Lesser Sunda Islands (absent in Lombok), eastwards as far as to the islands Timor, Letti, Moa, and Sermatta : also Australia and Tasmania. The absence of C. novaehollandiae in the Moluccas and New Guinea makes it most probable that the species has entered Australia via Timor (cf. MAYR, 1944).

Its centre of dispersal was presumably located in S. E. Asia, from which it has extended its range throughout Sunda Land and the chain of Lesser Sunda Islands to Australia. There is a notable interruption in the Malaysian distribution of this species by its absence from Sumatra and Borneo, these islands being inhabited by a special lowland form (striata). As at some time the whole of Sunda Land must have been inhabited by populations of $C$. novachollandiae, it can be presumed that $C$. striata represents the Sundaic offshoot of an original $C$. novaehollandiae stem. The similarity of the older members of the striata-Group mentioned above to $C$. novaehollandiae furnishes additional evidence in favour of this hypothesis. Therefore, $C$. striata must be an autochthonous element of the tropical Sunda Basin.

Only in the Malay Peninsula and the Antaman Islands have the specifically distinct forms novaehollandiae and striata been found occurring side by side. In the Malay Peninsula $C$. s. sumatrensis inhabits the eastern coastal lowlands, northwards to Central Perak, whereas $C$. $n$. larutensis inhabits the mountain slopes at about $1200-1700 \mathrm{~m}$ alt. between Northern Perak and Southern Selangor and Pahang (Robinson, 1928). According to Zeuner (I94I) and CoRBET (I94I) the southern half of Malaya was separated from the northern part of the peninsula during the Pleistocene periods of low sealevel by narrow sea-channels, which is the historical basis of an illdefined faunal convergence through the Isthmus of Kra and Padang Besar. This may also be the northern boundary not only of $C$. s. sumatrensis, but also of the Malayan distribution of $C$. $n$. larutensis, which in Southern Peninsular Siam merges into the slightly distinct Burmese and Indo-Chinese race siamensis (cf. Riley, 1938). It seems as if in the East Malayan portion of the Sunda Basin C. striata still inhabits the lowland biotope originally colonized in the Pleistocene, whereas $C$. novaehollandiae, being a Burmese faunal element, has succeeded in penetrating secondarily into Southern Malaya. At present it inhabits a slightly higher level than $C$. striata, from which it seems reproductively indifferent. The restricted Malayan ranges of these two species of CuckooShrikes might not be exclusively indicative of Pleistocene conditions, when 
"during the phases of high sea-level the Malay Peninsula formed a chain of islands, with Malaya proper as the largest member" (Zeuner, I94I, p. II9). Apart from historical influences the recent ranges may be also the result of important local climatical differences, as the regions north of Perak are at present rather dry.

In the Andamans $C$. n. andamana occurs alongside C.s. dobsoni. Since the Andamans were at no time connected to the continental Arrakan mountain range, after the end of the Pliocene, we can suppose, that the ancestors of present-day dobsoni reached the Andamans by a chance invasion from the Malay Peninsula. Judging by the fact that $C$. novaehol!andiae is the older (ancestrally) of the two species, it is probable that andamana inhabited these islands at the time of the arrival of the ancestors of dobsoni.

Contrary to the rule that the majority of the races of $C$. novaehollandiae is uniform grey below, certa:n forms, viz., macei, layardi, nipalensis, have barred underparts in the females and to some extent also in the males. These forms inhabit Ceylon and Eastern Peninsular India to the Burmese countries. The juvenile plumage of all races of the species is more or less strongly barred. Consequently, it can be concluded that barred underparts were the original type of colour pattern of this species. Ripley (l.c.) arrives at the same conclusion, when he states that " $C$. macei not only lives presumably somewhere near the ancestral home of the genus, but also probably resembles fairly closely the ancestral type of this species" (p. 384). We have thus reached the following reconstruction of the evolutionary history: the ancestral type of $C$. novaehollandiae, which apparently lived somewhere in the Burmese countries, had barred underparts, at least in the female, but probably in both sexes. From this type a uniform grey bird evolved (most races of $C$. novaehollandiae), which in turn gave rise to $C$. striata, of which the older forms are still a uniform grey in both sexes, but of which most races have secondarily barred females; while even in some Philippine races (and to some extent also in the Andaman race) the males have got strongly barred underparts.

RIPLEY (l.c.) has given convincing evidence that the species inhabiting the islands of the "Outer Banda Arc" (Timorlaut, Kei Islands, Ceram, Buru), Batjan, Ternate and Halmahera ( $C$. pollens, $C$. atriceps, $C$. fortis), as well as $C$. caledonica (New Caledonia, Loyalty Islands, New Hebrides, Banks Islands, and Solomon Islands) must be treated as geographical representatives of the $C$. novaehollandiae-Group, treating them as a superspecies. The members of these forms may show a black head or have a darkened plumage which includes the under-wingcoverts and under-tailcoverts. Taxonomically they are closely connected to each other by their rather large size and their remarkably broad and robust bills, which are the unmistakable characteristic of this group. $C$. pollens from the Kei Islands and $C$. caledonica from Melanesia resemble each other so closely, that, after the examination of specimens of both species, we must agree with RIPLEY (1.c., p. 386) that "positive identifi- 
cation would not be an easy matter". Nevertheless, the considerable geographical gap would "indicate that they are only a parallel of fspring of the same parent stock" (1.c.). Though we agree with RIPLEX, that the similarity between pollens and caledonica can only be the result of a convergent development, yet, we may also notice that a similar distribution pattern is found in the Ornithoptera-group of the butterfly genus Troides. According to ZeUner (1943) these butterflies have two widely separated centres of development, namely, the Moluccas and Solomon Islands. In order to explain this type of distribution ZEUNER has had the courage to introduce the theory of continental drift, based upon geological data : a withdrawal of the Australian block with New Guinea to the north of it "would suffice to straighten out the disturbed island chains and bring the Northern Moluccas near to the Solomons" (1.c. p. 173). This condition must have occurred in the Neogene, as late as the Pliocene. ZEUNER continues his arguments by stating, that the advance of New Guinea to its present position "must have been late enough for the Ornithoptera-group to have reached the Solomons before the Island chain Moluccas-Solomons was broken". This same conclusion when applied to the distribution of the species $C$. pollens, atriceps, fortis, and caledonica, indicates, that $C$. caledonica did not reach its present range via Australia, but along the still almost undisturbed Moluccas-Solomons island-chain. Independently of each other the melanistic species of the Kei Islands and of Melanesia must have arisen from a common stock.

In spite of the fact that according to RIPLEY (l.c., p. 390) C. schistacea from the Sula Islands superficially resembles the Philippine races mindorensis (Mindoro) and guillemardi (Sulu Islands), we consider, after an examination of specimens of schistacea and mindorensis, that the powerful bill and the dark plumage of schistacea link this species with the pollens-Group, rather than with striata. Additional evidence in support of this assumption is the fact that the Sula Islands represent the final coninuation of the "Outer Banda Arc", to which also the Kei Islands, Ceram and Buru belong.

In conclusion we are of the opinion that the disjointed distribution of the very closely related forms pollens, atriceps, fortis, schistacea, and caledonica, dates back to at least Pliocene geographical conditions. As during Pliocene, New Guinea was advancing in a northwesterly direction, disturbing the formerly unbroken island-chain Moluccas-Solomons, -it is not surprising to find that at present New Guinea is inhabited by a large blue-grey form of Coracina (caeruleogrisea) with a massive bill, which is only approached by members of the pollens-caledonica-Group. In $C$. caeruleogrisea the bill is even more robust than in $C$. fortis from Buru. Although RIPLEy has listed caeruleogrisea as an isolated form without known relatives, he has added some facts; which seem to indicate its relationship to $C$. pollens: the tawny coloration of the under-wingcoverts of caeruleogrisea can be found, though much less developed, in females and juveniles of pollens. $C$. caeruleogrisea agrees with 
the members of the caledonica-Group in frequenting a lowland biotope, being found in the southern plains of New Guinea, as well as the Aru Islands, in addition to hill-and mountain-forests up to $2000 \mathrm{~m}$ (MAYR, I94I). Consequently, $C$. caeruleogrisea can be considered to be a late-tertiary side-branch of the pollens-caledonica-Group, from which it has diverged more rapidly than its closest relatives.

\section{CORACINA LARVATA-GROUP (fig. 4)}

Contrary to the fact that the lowlands of the Sunda Islands are inhabited by two species of Coracina (striata, novaehollandiae), the mountain forests of Sumatra, Java, and Borneo are inhabited by such forms, which evidently belong to one species ( $C$. larvata). The importance of the racial differences of these mountain forms is reduced by the fact that the juveniles of the blackheaded Sumatran race melanocephala strongly resemble the adults of the Javanese race larvata, which have only the lores and forehead black. Adults of the Bornean race normani are intermediate, but juveniles of this race were not examined. $C$. larvata is a dark species, which somewhat resembles the personata-Group of $C$. novaehollandiae. Contrary to $C$. personata, $C$. lamata has the under-wingcoverts dark grey instead of white, and the bill is smaller and narrower, though of a similar shape as in personata. Nevertheless, larvata and novaehollandiae are rather closely related. The occurrence of ecologically representative races of both species in Java, as well as the disjointed and exclusively mountainous distribution of $C$. larvata indicate that the latter species was an inhabitant of the Sunda Land before the low rainforest had been invaded by a subsequent lowland form (novaehollandiae). Though it is probable that the ancestors of $C$. novaehollandiae arose from the same stock as $C$. larvata, we are of the opinion that the above mentioned facts furnish sufficient evidence to support the view that $C$. larvata is a relict of a still older wave of populations, apparently originating on the Asiatic mainland. Probably its ancestors colonized in Neogene times those Malayan mountains that formed the primordial back-bone of the later Sunda Land. Periods of high sea-level, submerging large parts of the Sunda Land, and the subsequent dispersal of newly developed lowland forms, have disrupted the once continuous range of $C$. larvata and have brought about its ecological isolation.

Mountain forms of Coracina with rather short bills of $C$. larvata-type, occur in Celebes (temmincki) and in New Guinea (longicauda). Both have a rather aberrant plumage.

C. temmincki is ultramarine blue all over, but the juvenile plumage shows the cross-barring and dark grey coloration found in many adults and juveniles of forms of Coracina. We agree with Ripley (1.c., p. 393) that when the blue is suppressed, temmincki resembles the caledonica-Group. Although the shape of the bill of the adults of temmincki varies to a large extent, irrespective of range and sex, it is closest to that found in $C$. larvata. 
C. longicauda shows, apart from other characteristics, a remarkably long tail and very loose dorsal feathering, but the black head and weak bill are reminiscent of C. l. melanocephala.

Though the history of these species cannot be traced back, yet, their isolated montane distribution, and their structural similarity appear to us indicative of a similar origin to that of $C$. larvata. We suggest that these species are the remnents of the same Tertiary wave of populations that peopled the Sunda Mountains and ultimately penetrated into the eastern part of the archipelago. During the long time that elapsed the Celebesian and New Guinean of fshoots of this wave acquired their rather aberrant mode of plumage. This is not an uncommon phenomenon in many of the older Celebes and New Guinea forms, since these islands are known to have acted as important centres of avian evolution.

C. parvu'a from Halmahera has been listed as a race of $C$. personata by Mathew's and as a race of $C$. larvata by Hachisuka (who also included personata). It is a small bird with a dark bluish grey plumage, black throat and loral mask and a small bill, which resembles that of $C$. $l$. melanocephala both in shape and in size. Taxonomically parvula could well be included in the larvata-Group, from which it has been isolated since its early arrival in the Northern Moluccas. In spite of its central position in the Moluccas, Halmahera has a rather isolated avifauna with many old elements. ZEUner (I943) arrived at the same conclusion when studying the evolutionary history of the Bird-wing Butterflies. According to this author the isolation of the Ornithoptera priamus Species-Group, occurring on Halmahera, Batjan, and Obi, "has to be placed very early, certainly before the beginning of the Pleistocene" (p. I66). If it is accepted that $C$. parvu!a belongs to the larvata-Group, it follows from the age of this Group, that the same conclusion holds good for the date of immigration of this species into Halmahera.

Edolisoma abbotti from Celebes has been listed by RIPLEY (l.c.) as a member of the genus Coracina and a close relative of $C$. parvula. Though we have compared four specimens of $E$. abbotti with the types of $C$. parvula in the Leiden Museum, we cannot see any similarities between these species, other than general size and lack of distinct white edges to the wing-feathers. Abbotti has the feeble and sharply pointed bill characters attributed to the genus Edolisoma, which are distinctive generic characteristics when compared with Coracina. The bill of abbotti proved to be even more gracile and sharply pointed than that of the other Celebesian species $E$. morio, which is generally accepted to be an undoubted member of the genus Edolisoma. Neither STRESEMANN (in litt., I948), nor the present authors can see in abbotti anything else than a true, though in the partly white underparts somewhat aberrant, member of Edolisoma! 


\section{CORACINA PAPUENSIS-GROUP (fig. 7)}

C. robusta, papuensis, and leucopygia resemble each other so closely in the adult state that we are wholly in agreement with RIPLEY in uniting these forms into one superspecies, of which the constituting elements are geographically strictly representative. However, the juvenile plumage of $C$. robusta from Southeastern and Southern Australia is quite unlike that of the other species, its black head and barred underside exhibiting a close similarity with C. novaehollandiae and its relative species. Moreover, the weak bill of the papuensis-superspecies is reminiscent of the relatively small, though broad, bill of $C$. n. novaeho!landiae (= "parvirostris" of former authors) from the same area as $C$. robusta. In spite of its rather wide range, the papuensissuperspecies has neither direct relatives on the Sunda Islands, nor on the Asiatic continent. The Australian forms of $C$. novaehollandiae seem to be its only close relatives. On account of the fact that robusta and papuensis seem to be ecologically distinct from novaehollandiae, inhabiting a more dry savannah vegetation rather than more luxuriously forested regions, we can assume that the papuensis-superspecies is an Australian of fshoot of the novaehollandiae-stem from which it diverged not only by geographical but in addition by ecological isolation. This assumption indicates that we are in agreement with RIPLEY (1.c.), in suggesting that the papuensis-superspecies "has not evolved entirely independently, but rather stems from an older continental form which has become lost .or redirected into another form" (p. 39I). The "older continental form" might be the Southeast Asiatic root from which all forms belonging to the caledonica-superspecies (RIPLEY) have originated, whereas the "redirected" form might be the Australian races of $C$. novachollandiae. Consequently, the range of the papuensis-superspecies must have turned backwards towards the Asiatic continent by spreading not only over the Melanesian Islands (Solomons and Bismarck lslands), but also over New Guinea, East-Papuan Islands, the Aru Islands, and northern Moluccas (absent in Sula Islands), as far as to Celebes. In the latter island a slightly distinct form (leucopygia) occurs, which hardly warrants specific distinction (white rump patch; yellow iris). The absence of this superspecies in the Lesser Sunda Islands and the Kei Islands is indicative of the course of its distribution, which must have followed Australia - New Guinea - West Papuan Islands - Moluccas - Celebes. Pleistocene periods of low sea-level connecting New Guinea with Australia and the Aru Islands, and bringing some of the Papuan Islands nearer to New Guinea, must have facilitated the dispersal of $C$. $p a$ puensis as a lowland-species over the Sahul Land. Since its racial development is rather slight and only quantitative, and the same race of $C$. papuensis has been found in Northwest Australia and the Aru Islands (hypo!euca; cf. MAYR, I94I), its colonization of New Guinea and the northern Moluccas must have taken place rather recently, in the Pleistocene and Holocene. This 
is in agreement with the earlier conclusion that $C$. leucopygia is a relatively recent arrival of Celebes. It is a common bird of the lowlands in all cultivated areas and in native villages (STREsemanN, 1940), whereas the other two Celebesian species of Coracina are rather. locally distributed (bicolor), or exclusively inhabiting mountain forests (temmincki). The same holds good for the Melanesian islands in which papuensis and caledonica occur side by side. Caledonica lives in well wooded country, in the lowlands as well as on the hills and in the mountains, whereas papuensis is "extremely common along the coast, in coconut plantations, secondary growth, along edge of forest" (MAYR, 1945, p. 249).

\section{CORACINA LINEATA-GROUP (fig. 3)}

Australia is inhabited by what, according to RIPLEY (l.c.), is the representative of a third superspecies, but only occurring in the eastern parts $(C$. lineata). It is a small form with a rather weak, though relatively broad bill, which, however, is quite distinct from the narrow type of bill found in Edolisoma. The males of some races and all females have narrowly barred undersides, though to a different degree, and all have barred under-wingcoverts. In general appearance, as well as in size and in shape of bill, $C$. lineata resembles the African forms of the genus (pectoralis, caesius; also "Coquus" newtoni from Réunion and. "C." typicus from Mauritius). This resemblance to Ethiopian forms is still more apparent when $C$. boyeri is included as a related species of $C$. lineata. In addition to the distributional arguments, a few taxonomic characters support the inclusion of these two forms into one phylogenetic group: they are of the same - rather small general size, the upperparts are of the same bluish grey coloration, and the shape of the bill is similar; moreover, the juvenile and immature plumages of boyeri are much less blue than the adult one, making the species less aberrant in this respect. Though it is certainly a case of parallel development with $C$. boyeri, one should notice that wholly purplish blue (azurea) and bluish grey (caesius) forms of Coracina are also found in Africa.

C. lineata has no close relatives on the Asiatic continent. It inhabits the hill forests of the central mountains and the northern, originally volcanic, belt of New Guinea, including also Waigeu, the Tamrau and Arfak Mountains, Numfoor, and the East Papuan Islands New Ireland and the Solomons. This range represents the interrupted, geologically oldest, part of the New Guinea block. Its continuous range in Eastern Australia from Cape York south to New South Wales, covers the geologically most stable portion of the Australian continent in which many very old faunistic elements have survived as relicts.

C. boyeri is an aberrant lowland form, which has not been found above $800 \mathrm{~m}$ (MAYR, I94I); it occurs in two slightly distinct races north and south 


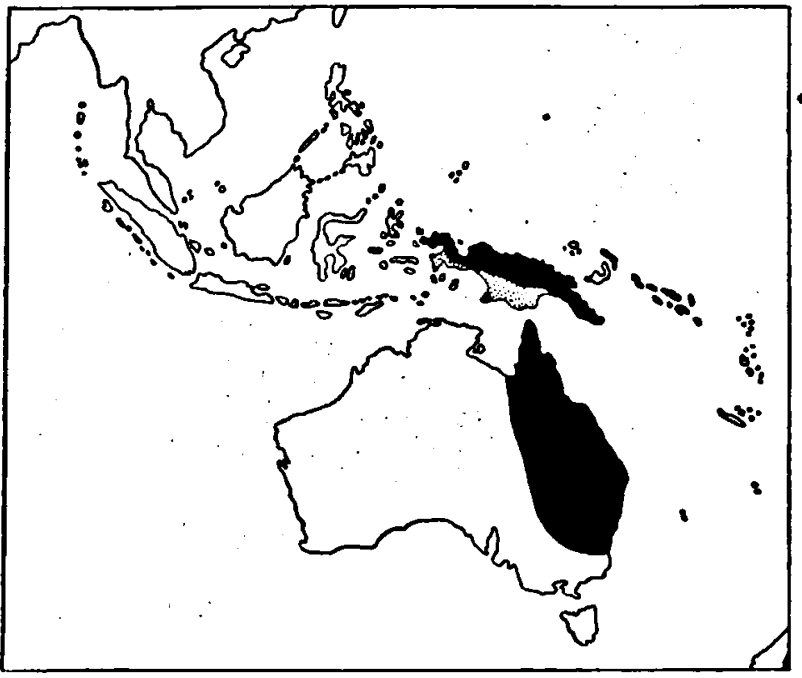

Fig. 3. Coracina lineata-Group: oldest relict distribution. Non-typical form with spotted area: boyeri.

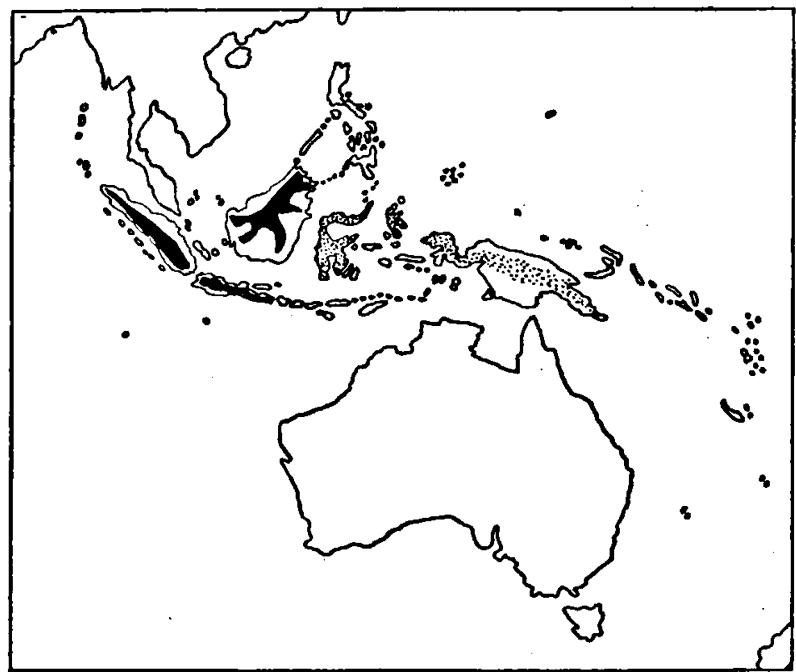

Fig. 4. Coracina larvata-Group: mountain relicts. Non-typical forms with spotted area: tcmmincki, parvula, longicauda. 


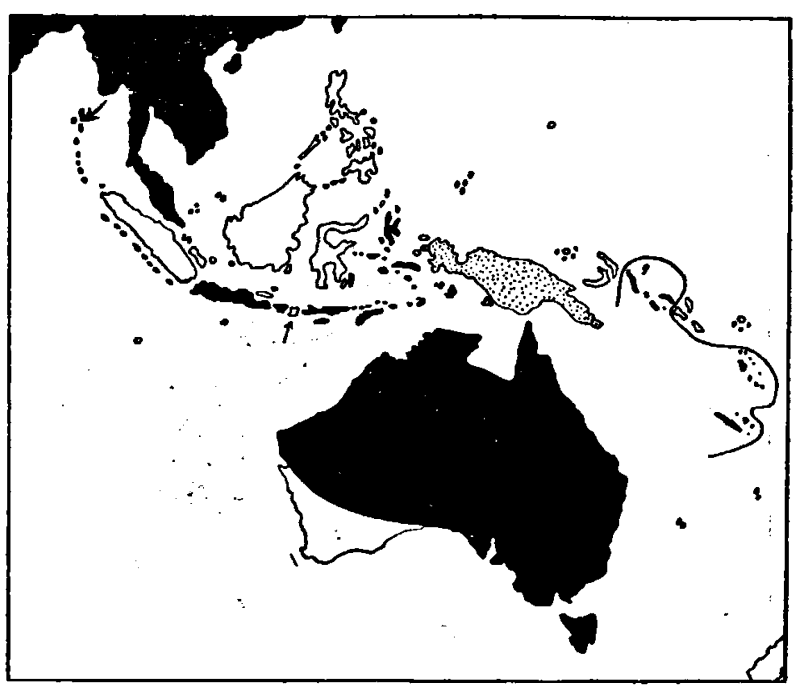

Fig. 5. Coracina novaehollandiae-Group: widest AsiaticAustralian range. Non-typical form with spotted area: caeruleogrisea.

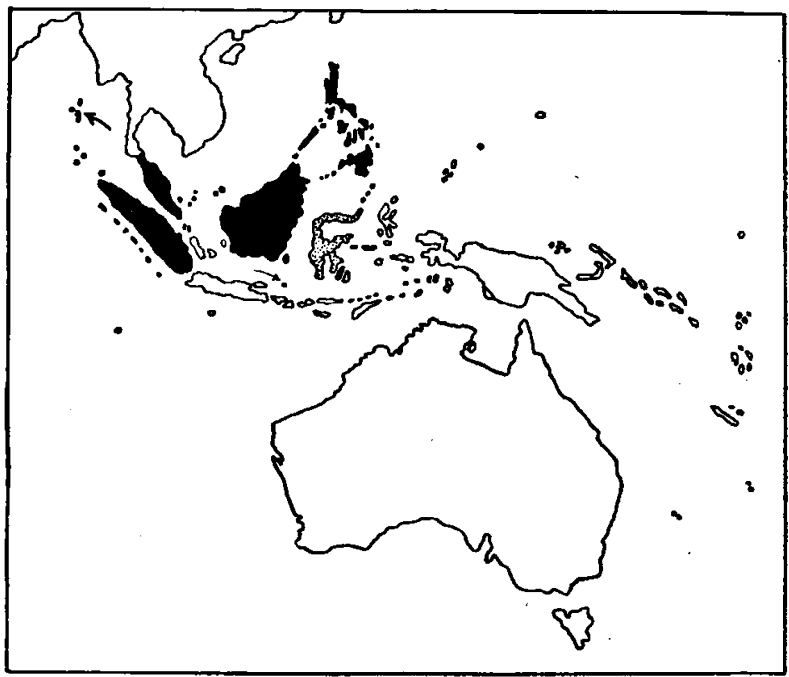

Fig. 6. Coracina striata-Group: Pleistocene Sundaic development. Non-typical form with spotted area: bicolor. 


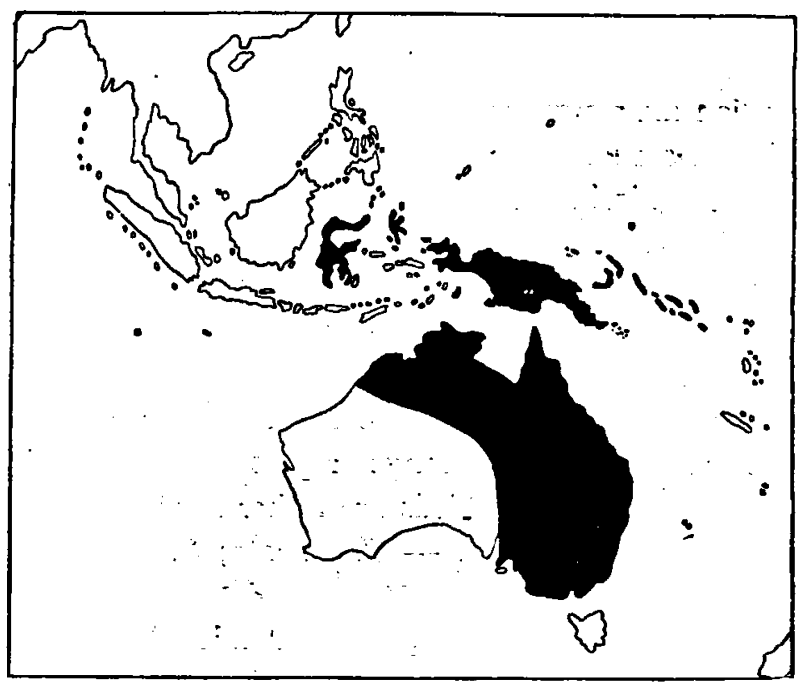

Fig. 7. Coracina papuensis-Group: return from Australia into Asiatic direction.

of the central mountain range of New Guinea. It is considered to be a strongly differentiated offshoot of the common stem from which also $C$. lineata originated. Consequently, lineata and boyeri must be the oldest members of the genus Coracina in the Indo-Australian region. The structural characteristics of these two small species and the above mentioned superficial resemblances to the African forms, are arguments in favour of the common South Asiatic origin of all Ethiopian and Indo-Australian forms of Coracina.

\section{CONCLUSIONS}

Ripley (I94I) recognizes I9 Indo-Australian forms of Coracina, which in the present paper have been arranged into 5 groups. In contrast to RIPLEy's method of working, the relative shape of the bill has been of much help to us in grouping the various forms of the genus. Each group represents a locally evolved species-group, or a distinct wave of populations, which has extended its range all over the Indo-Australian archipelago, and has left behind one or more geographically often widely separated island forms. These forms may still have some taxonomic characters in common or may agree in the general biotope or in the competition with other forms of the genus. The historical basis of the distribution of these groups has been discussed. In the old groups the taxonomic differences in isolated insular or mountain forms have become remarkably wide, resulting in the fact that all five groups cannot be treated as equivalent superspecies of which representative distribution may not be the only criterion. We have attempted to show that the subsequent waves of populations which peopled the Indo-Australian Archipelago, radiated from 
Southeastern Asia. In this respect we are in agreement with RIPLEY (1.c.). Furthermore, we have tried to show that the Pleistocene tropical Sunda Basin and the Australian mainland have acted as important centres of speciation.

The following is a summary of our conciusions in a historical sequence.

I. The oldest recognizable wave must be of a Neogene date. Its members are rather small and had originally barred underparts. Remnants of this wave occur in Eastern Australia, North and South-East New Guinea, and the East Papuan Islands. Also in Africa! - C. lineata; C. boyeri (group V; fig. 3 ).

2. The inhabitants of the mountains of the Sunda Islands, Celebes, Halmahera, and New Guinea are considered to represent the second Neogene wave. These widely separated mountain ranges represent the oldest and most stable portions of the archipelago. The birds are rather small, and two forms of this group are strongly differentiated. - C. larvata; C. parvula; C. temmincki; C. longicauda (group III; fig. 4).

3. A Pliocene wave of populations has extended its range as far east as the whole of Australia and Tasmania and to the New Hebrides and Loyalty Islands. A geological basis has been developed for explaining the fact that the inhabitants of the islands of the Outer Banda Arc are taxonomically closer to those of Melanesia than to those of Australia, as also for the fact that New Guinea is inhabited by an aberrant of fshoot of this widely distributed speciesgroup. Discontinuities in the Sundaic and Philippine parts of the ranges of these populatons are explained by the presence in these islands of lowland members of the next group. Probably the original members of this wave had barred underparts, though white under tailcoverts. This condition is still found in some of the continental forms ( $C$. n. macei and relative races), which we consider to be still of the ancestral type. In this group also a tendency to ( $I$ ) a wholly black plumage, beginning with the head, and (2) a very robust and broad bill, is noticeable. The group corresponds with RIPLEY's caledonicasuperspecies $-C$. novaehollandiae; $C$. fortis; $C$. atriceps; $C$. schistacea; $C$. pollens; $C$. caledonica; $C$. caeruleogrisea (group II, fig. 5 ).

4. Speciation phenomena in the tropical Sunda-lowlands during the alternative Pleistocene periods of low and high sea-level, have caused the development of a distinct lowland group (striata) from an ancestral novaehollandiae-stem. It has occupied all coastal plains and lowlands of the Sunda Shelf, except Java, but including the Philippines. Its members, which form the most recently developed group of the genus, show a secondary tendency to barring of the underparts, not only in the female, but also in the male sex. Pleistocene members of this group have succeeded in colonising Celebes through the Philippines and the Sulu Islands, resulting in the development of a separate Celebesian species. - C. striata; C. bicolor (group I, fig. 6).

5. A backwardly directed wave has originated from the novaehollandiaestock, radiating from eastern Australia. Its specific separation has been probably based not only on geographical, but also on ecological isolation. The 
slightly developed subspecific distinctions in the most widely-spread species of this group ( $C$. papuensis) indicate its rather recent dispersal through Cape York, New Guinea, Moluccas, and Celebes. In the latter locality it has developed a slightly distinct endemic species (leucopygia). C. leucopygia represents the most recent immigration of this group into Celebes. $-C$. robusta; C. papuensis; C. leucopygia (group IV, fig. 7).

With the exception of $C$. striata and $C$. leucopygia, all forms grouped here as systematic species of Coracina, have become isolated or differentiated in pre-pleistocene times. During the Pleistocene the development of $C$. striata took place in the Sunda Land, whereas $C$. leucopygia branched off from the papuensis-stem in Celebes. Many recent subspecies, however, became established in the Pleistocene and Holocene.

\section{LITERATURE}

Beaufort, L. F. DE, 1926. Zoögeographie van den Indischen Archipel. Haarlem (Volksuniversiteitsbibliotheek).

Corbet, A. S., I94I. The distribution of Butterflies in the Malay Peninsula (Lepid.). Proc. Roy. Ent. Soc. London, Ser. A I6, p. I0I-I16.

Delacour, J., 1946. Notes on the taxonomy of the birds of Malaysia. Zoologica, New York Zool. Soc. 3I, p. 2.

\& E. Mayr, I946. Birds of the Philippines. New York (MacMillan Cie).

Mayr, E., I94I. List of New Guinea birds. New York (Am. Mus. Nat. Hist.) p. 102-IO4.

-, I944. Timor and the colonization of Australia by birds. The Emu 44, p. I20-I2I.

- 1945. Birds of the Southwest Pacific. New York (MacMillan Cie).

Riley, J. H., 1938. Birds from Siam and the Malay Peninsula etc. Bull. U.S. Nat. Mus. I72, p. $277-278$.

Ripley, S. D., I94I. Notes on the genus Coracina. The Auk 58, p. 38I-395.

Robinson, H. C., 1928. Birds of the Malay Peninsula; I. London (Witherby).

StresemanN, E., I940. Die Vögel von Celebes. J. f. Orn. 88, p. I20-124.

Voous, K. H., I947. On the history of the distribution of the genus Dendrocopos. Wageningen. Also: Limosa 20, p. I-142.

Zeuner, F. E., 194I. Geology, climate and faunal distribution in the Malay Archipelago. Proc. Roy. Ent. Soc. London, Ser. A I6, p. I17-123.

- I943. Studies in the systematics of Troides Hübner (Lepidoptera, Papilionidae) and its allies. Trans. Zool. Soc. London 25, p. 107-184. 